ISSN 0258-7122 (Print), 2408-8293 (Online)

Bangladesh J. Agril. Res. 43(1): 99-108, March 2018

\title{
STABILITY OF HYBRID RICE GENOTYPES FOR GRAIN YIELD AND MATURITY
}

\author{
M. J. HASAN ${ }^{1}$, M. U. KULSUM ${ }^{2}$ E. $\operatorname{HOSSAIN}^{3}$ \\ AND N. M. F. RAHMAN ${ }^{4}$
}

\begin{abstract}
An experiment was conducted using nine hybrid rice genotypes along with two inbred standard check varieties in five different locations of Bangladesh to assess their stability in terms of grain yield and maturity in diverse environments. For this, adaptability, stability, genotype $\times$ environment $(\mathrm{G} \times \mathrm{E})$ interaction effect for grain yield and maturity of 11 rice varieties in five agro ecological zones in Bangladesh were assessed during T. Aman season of 2015. The analysis of variance for growth duration and grain yield ( $t / h a)$ for genotypes, environment and genotype-environment interaction were highly significant at $1 \%$ level of probability indicating the variable response of genotypes and environments. The hybrid genotypes IR79156A/BRRI20R, BRRI hybrid dhan3, BRRI33R/BRRI26R, BRRI hybrid dhan4, standard check variety BRRI dhan49 and BR11 had high yield performance and widely adapted to all environments and these were non sensitive to environmental interactive forces, while the hybrids BRRI7A/BRRI31R, IR79156A/BasmatiR and SL-8 were sensitive to environmental interaction. Environment such as Gazipur (E1) and Faridpur (E3) having positive IPCA1 score and positive interaction with the hybrids BRRI7A/BRRI13R, SL-8H and IR79156A/BasmatiR were considered as the favourable environments for these hybrids.
\end{abstract}

Keywords: AEZ, adaptability, AMMI analysis.

\section{Introduction}

Hybrid rice is one of the proven technologies in the world for addressing food security and self-sufficiency in rice. Stability in yield is one of the vital desirable properties of a genotype to be released as a variety for cultivation. Presently, rice has special position as a source of food supply over $75 \%$ of Asian population and more than three billion of world population which represents 50 to $80 \%$ of their daily calorie intake (Amirjani, 2011). This population will increase to over 4.6 billion by 2050 (Honarnejad et al., 2000) which demands more than $50 \%$ of rice needs to be produced what is produced at present to cope with the growing population (Srividya et al., 2010).

Among the many available genetic approaches being exploited to break the yield barrier in rice, hybrid rice technology is considered as one of the promising,

${ }^{1}$ Principal Scientific Officer, Hybrid rice Division, Bangladesh Rice Research Institute (BRRI), Gazipur-1701, ${ }^{2}$ Scientific Officer, Hybrid rice Division, BRRI, Gazipur-1701, ${ }^{3}$ Deputy Director (Admin \& Common service), BRRI, Gazipur-1701, ${ }^{4}$ Senior Scientific Officer, Statistics Division, BRRI, Gazipur-1701, Bangladesh. 
practical, sustainable and eco-friendly options to break the yield ceiling in rice (Sheeba et al., 2009). The general rice breeding scheme includes evaluating a number of genotypes at various stages and testing selected ones at several locations. Information on genotype $\times$ environment interaction leads to successful evaluation of stable genotype, which could be used for general cultivation. Yield is a complex quantitative character and is greatly influenced by environmental fluctuations; hence, the selection for superior genotypes based on yield per se at a single location in a year may not be very effective (Shrestha et al., 2012). In the process of evaluation of genotypes under different environmental situation stability performance for yield has been an effective part of any breeding program. Considerable number of methods have been developed to analyze genotype $\times$ environment interaction and phenotypic adaptability. In them the additive main effect and multiplicative interaction analysis (AMMI) has been broadly applied in the statistical analysis of all-environment genotype trials (Gauch and Zobel, 1997). AMMI biplot analysis is argued to be an useful tool to diagnosticate GEI patterns graphically. In AMMI, the additive portion is separated from interaction by analysis of variance (ANOVA). The biplot show PCA scores decorated against each other gives apparent inspection and explanation of genotype $\times$ environment interaction components. The present investigation of hybrid rice was started to analyze $\mathrm{G} \times \mathrm{E}$ interaction using AMMI model and to assess stability and adaptability of genotypes in various environments.

\section{Materials and Methods}

The experiments were conducted under hybrid rice division of Bangladesh Rice Research Institute (BRRI) at five different agro-ecological zones (Gazipur =E1, Rangpur $=\mathrm{E} 2$, Faridpur $=\mathrm{E} 3$, Rajshahi $=\mathrm{E} 4$ and Sonagazi $=\mathrm{E} 5$ ) during $\mathrm{T}$ Aman season of 2015. The entry comprises four promising, 5 released rice hybrid varieties and two standard inbred checks BRRI dhan 49 and BR11 (Table 1). The experiments were carried out in a randomized complete block design with three replications. The size of each experimental plot was $5 \times 6 \mathrm{~m}$. Standard agronomic practices were followed and plant protection measures were taken as required. Two border rows were used to minimize the border effects. Growth duration were recorded and the grain yield (t/ha) data was estimated and adjusted at $14 \%$ moisture.

Table 1. List of materials with sources

\begin{tabular}{c|c|c|c|c|c}
\hline $\begin{array}{r}\text { SL } \\
\text { No. }\end{array}$ & Designation & Sources & $\begin{array}{c}\text { SL } \\
\text { No. }\end{array}$ & Designation & Sources \\
\hline 1 & BRRI33A/BRRI26R & BRRI & 7 & Heera F & Supreme Seed Company \\
2 & BRRI7A/BRRI31R & BRRI & 8 & Teea F & Lal Teer Seed (BD) Ltd. \\
3 & IR79156A/BRRI20R & BRRI & 9 & BRRI hybrid dhan4 & BRRI \\
4 & BRRI hybrid dhan3 & BRRI & 10 & BRRI dhan49 & BRRI \\
5 & IR79156A/BasmatiR & BRRI & 11 & BR11 & BRRI \\
6 & SL-8H & BADC & & \\
\hline
\end{tabular}




\section{Statistical analysis}

AMMI model was used to quantify the effect of different factors (genotype, location) of the experiment. The AMMI statistical model is most appropriately termed as a hybrid model. It makes use of standard ANOVA procedures to separate the additive variance from multiplicative variance (genotype by environment interaction). Then it uses a multiplicative procedure- PCA- to extract the pattern from the $\mathrm{G} \times \mathrm{E}$ portion of the ANOVA (Zobel et al., 1988). Thy hybrid model is:

$$
Y_{g e}=\mu+\alpha_{g}+\beta_{e}+\sum_{n=1}^{N} \lambda n \gamma_{g n} \delta_{e n}+\rho_{g e}
$$

Where:

$$
\begin{aligned}
& Y_{g e}=\text { yield of the genotype (g) in the environment (e) } \\
& \mu=\text { grand mean } \\
& \alpha_{g}=\text { genotype mean deviation } \\
& \beta_{e}=\text { environment mean deviation } \\
& \mathrm{N}=\text { No. of IPCAs (Interaction Principal Component Axis) retained in he } \\
& \text { model. } \\
& \lambda n=\text { singular value for IPCA axis } \mathbf{n} \\
& \gamma_{g n}=\text { genotype eigenvector values for IPCA axis } \mathbf{n} \\
& \delta_{e n}=\text { environment eigenvector values for IPCA axis } \mathbf{n} \\
& \rho_{g e}=\text { the residuals }
\end{aligned}
$$

The model further provides graphical representation of the numerical results (Biplot analysis) with a straight-foreword interpretation of the underlying causes of G x E (Gauch, 1988), (Kempton, 1984), (Bradu and Gabriel, 1978).

\section{Results and discussion}

Significant Mean Sum of Squares (MSS) of genotypes, environment and G×E interaction for growth duration and yield were estimated (Table 2). The highly significant effects of environment indicated the differences in environmental factors of the locations. Significant MS for genotypes indicated differential genotypic composition of the genotypes. The variation in soil composition and other factors across the different environments were considered as the major underlying causal factors for the $\mathrm{G} \times \mathrm{E}$ interaction. The analysis of variance of AMMI showed that the mean sum of squares (MSS) due to treatments, genotypes, environments and genotype $x$ environment interactions were 
significant, indicating broad range of diversity existed among genotypes (Anandan et al., 2009, Vijayakumar et al., 2001). Environment relative magnitude was much higher than the genotype effect, suggesting that genotype performance was influenced more by the environmental factors. Analysis of variance based on AMMI model for grain yield is presented in Table 2. The effects of genotype $\times$ environment interaction could be divided into four components, i.e.; IPCA1, IPCA2, IPCA3 and IPCA4 where IPCA1 and IPCA2 were significantly different but IPCA 3 and IPCA4 were not significantly different.

Table 2. Analysis of variance of the $G \times E$ interaction of hybrid rice for growth duration and grain yield

\begin{tabular}{l|c|c|c}
\hline \multirow{2}{*}{ Source of variation } & \multirow{2}{*}{ df } & \multicolumn{2}{|c}{ Mean sum of squares } \\
\cline { 3 - 4 } & & Growth duration & Yield (t/ha) \\
\hline Genotypes (G) & 10 & $1133.73^{* *}$ & $14.18^{* *}$ \\
Environment (E) & 4 & $74.13^{* *}$ & $2.09^{* *}$ \\
Replication & 2 & $44.58^{* *}$ & $1.66^{* *}$ \\
Interaction G x E (GEI) & 40 & $10.30^{* *}$ & $0.51^{* *}$ \\
AMMI Component 1 & 13 & $7.66^{* *}$ & $0.34^{* *}$ \\
AMMI Component 2 & 11 & 1.82 & $0.15^{*}$ \\
AMMI Component 3 & 9 & 1.74 & 0.05 \\
AMMI Component 4 & 7 & 0.31 & 0.03 \\
G×E (Linear) & 10 & $8.46^{* *}$ & $0.31^{* *}$ \\
Pool deviation & 30 & 1.76 & 0.12 \\
Pooled error & 88 & 5.45 & 0.21 \\
\hline
\end{tabular}

** Significant at $1 \%$ level of probability, * Significant at $5 \%$ level of probability.

Stability of the tested hybrids based on growth duration are presented in Table 3.The hybrids IR79156A/BasmatiR, SL-8H, Heera and BRRI hybrid dhan4 exhibiting negative phenotypic index $(\mathrm{Pi})$, insignificant regression coefficient (bi) and deviation from regression $\left(\mathrm{S}^{2} \mathrm{di}\right)$ values can be considered as stable across all environments with shorter growth duration. Kulsum et al. (2015) showed the genotype HS273, Heera 2, Doel, BRRI dhan29 and BRRI hybrid dhan1 are stable over all environments with short growth duration. Short growth duration is required for development of early maturing variety. BRRI hybrid dhan3 had negative phenotypic index (Pi), significant regression coefficient (bi) and insignificant deviation from regression $\left(\mathrm{S}^{2} \mathrm{di}\right)$ values which indicated that this hybrid would be highly responsive to the favorable environments of E4 and E5. 
Table 3. Stability analysis for growth duration of promising hybrid rice genotypes in

\begin{tabular}{|c|c|c|c|c|c|c|c|c|c|c|}
\hline \multirow{2}{*}{$\begin{array}{l}\text { En. } \\
\text { no }\end{array}$} & \multirow[b]{2}{*}{ Genotypes } & \multicolumn{6}{|c|}{ Environments } & \multirow{2}{*}{$\begin{array}{c}\text { Phenotypic } \\
\text { Index } \\
(\mathrm{Pi})\end{array}$} & \multirow[b]{2}{*}{ bi } & \multirow[b]{2}{*}{$\mathrm{S}^{2} \mathrm{di}$} \\
\hline & & E1 & E2 & E3 & E4 & E5 & $\begin{array}{c}\text { Overall } \\
\text { Mean }\end{array}$ & & & \\
\hline 1 & BRRI33A/BRRI26R & 115.7 & 116.0 & 114.3 & 111.3 & 115.0 & 114.5 & 2 & 1.14 & 0.75 \\
\hline 2 & BRRI7A/BRRI31R & 115.3 & 119.0 & 117.3 & 116.3 & 115.7 & 116.7 & 4.2 & 0.14 & 2.86 \\
\hline 3 & IR79156A/BRRI20R & 112.7 & 109.7 & 114.7 & 106.7 & 110.7 & 110.9 & -1.6 & 1.70 & 3.63 \\
\hline 4 & BRRI hybrid dhan 3 & 105.7 & 106.7 & 106.0 & 104.7 & 105.3 & 105.7 & -6.8 & $0.38^{*}$ & 0.30 \\
\hline 5 & IR79156A/BasmatiR & 108.3 & 105.7 & 107.7 & 102.3 & 106.3 & 106.1 & -6.4 & 1.48 & 0.72 \\
\hline 6 & SL-8H & 107.0 & 105.7 & 104.7 & 103.3 & 104.7 & 105.1 & -7.4 & 0.76 & 0.76 \\
\hline 7 & Heera & 111.7 & 107.7 & 110.7 & 104.3 & 109.7 & 108.8 & -3.7 & 1.74 & 2.13 \\
\hline 8 & Teea & 107.0 & 106.3 & 106.7 & 107.3 & 105.7 & 106.6 & -5.9 & $0 . \overline{1} 6^{*}$ & 0.47 \\
\hline 9 & BRRI hybrid dhan 4 & 109.7 & 109.7 & 109.0 & 105.0 & 107.7 & 108.2 & -4.3 & 1.28 & 0.26 \\
\hline 10 & BRRI dhan49 & 132.7 & 132.7 & 134.3 & 123.0 & 130.7 & 130.7 & 18.2 & $2.91^{*}$ & 1.37 \\
\hline 11 & BR11 & 127.0 & 127.0 & 123.0 & 127.3 & 127.7 & 126.3 & 13.8 & -0.36 & $4.35^{*}$ \\
\hline & Mean & 114.2 & 114.3 & 113.6 & 108.5 & 112.2 & 112.5 & & & \\
\hline & $\mathrm{E}$ index (Ij) & 1.7 & 1.8 & 1.1 & -4.0 & -0.3 & & & & \\
\hline & $\mathrm{CV}(\%)$ & 2.13 & 1.13 & 1.92 & 2.20 & 1.98 & & & & \\
\hline & $\operatorname{LSD}(0.05)$ & 4.12 & 2.18 & 3.72 & 4.13 & 3.79 & & & & \\
\hline
\end{tabular}

* indicates slopes significantly different from the slope for the overall regression which is 1.00 .

E1= Gazipur, E2= Rangpur, E3= Faridpur, E4= Rajshahi and E5= Sonagazi.

Standard check variety BRRI dhan49 had positive phenotypic index (Pi), significant regression coefficient (bi) and non significant $\mathrm{S}^{2}$ di value indicating higher growth duration and highly responsive to the favorable environments of E1, E2 and E3. Standard check variety BR11 had positive phenotypic index (Pi), insignificant regression coefficient (bi) and $\mathrm{S}^{2}$ di value indicating late maturing in E4 and E5. The promising hybrid BRRI33A/BRRI26R had higher mean value than the grand mean, positive Pi value, insignificant regression coefficient (bi) and deviation from regression $\left(S^{2}\right.$ di) values indicating stable hybrid over all environments for longer days to maturity (Table 3). Aditya et al., (2010) observed the genotype BRRI dhan29-SC3-28-L3 had short growth duration and stable over locations.

Among the hybrids IR79156A/BRRI20R had the highest mean grain yield, positive phenotypic index (Pi), insignificant regression coefficient (bi) and deviation from regression $\left(\mathrm{S}^{2}\right.$ di) values indicating stable hybrid over all environments E1, E2, E3, E4 and E5. It is the best hybrid for grain yield. Kulsum et al. (2015) also observed thats the genotype ACI93024 was more adapted to a wide range of environments. 
Table 4. Stability analysis for grain yield (t/ha) of promising hybrid rice genotypes in five environments

\begin{tabular}{|c|c|c|c|c|c|c|c|c|c|c|}
\hline \multirow[b]{2}{*}{$\begin{array}{c}\text { En. } \\
\text { no }\end{array}$} & \multirow[b]{2}{*}{ Genotypes } & \multicolumn{6}{|c|}{ Environments } & \multirow{2}{*}{$\begin{array}{c}\text { Phenotypic } \\
\text { Index } \\
(\mathrm{Pi})\end{array}$} & \multirow[b]{2}{*}{ bi } & \multirow[b]{2}{*}{$\mathrm{S}^{2} \mathrm{di}$} \\
\hline & & E1 & $\mathrm{E} 2$ & E3 & $\mathrm{E} 4$ & E5 & $\begin{array}{c}\text { Overall } \\
\text { Mean }\end{array}$ & & & \\
\hline 1 & $\begin{array}{l}\text { BRRI33A/ } \\
\text { BRRI26R }\end{array}$ & 6.47 & 6.47 & 6.53 & 6.28 & 5.77 & 6.30 & 0.54 & 0.31 & 0.12 \\
\hline 2 & $\begin{array}{l}\text { BRRI7A/ } \\
\text { BRRI31R }\end{array}$ & 6.65 & 5.56 & 6.37 & 5.32 & 5.71 & 5.92 & 0.16 & 1.89 & 0.12 \\
\hline 3 & $\begin{array}{l}\text { IR79156A/ } \\
\text { BRRI20R }\end{array}$ & 7.57 & 7.51 & 7.70 & 7.59 & 6.98 & 7.47 & 1.71 & 0.35 & 0.10 \\
\hline 4 & $\begin{array}{l}\text { BRRI hybrid } \\
\text { dhan3 }\end{array}$ & 6.98 & 6.73 & 6.81 & 6.76 & 6.75 & 6.80 & 1.04 & $0.38^{*}$ & 0.00 \\
\hline 5 & $\begin{array}{l}\text { IR79156A/ } \\
\text { BasmatiR }\end{array}$ & 6.60 & 4.40 & 6.36 & 5.52 & 5.99 & 5.77 & 0.01 & 3.06 & 0.22 \\
\hline 6 & SL-8H & 6.76 & 4.68 & 6.45 & 5.75 & 6.19 & 5.96 & 0.2 & 2.87 & 0.18 \\
\hline 7 & Heera & 5.43 & 4.36 & 4.06 & 5.04 & 4.78 & 4.73 & -1.03 & 1.13 & 0.28 \\
\hline 8 & Teea & 5.16 & 4.61 & 4.14 & 4.88 & 4.56 & 4.67 & -1.09 & 0.60 & 0.16 \\
\hline 9 & $\begin{array}{l}\text { BRRI hybrid } \\
\text { dhan4 }\end{array}$ & 6.32 & 6.22 & 6.38 & 6.11 & 6.02 & 6.21 & 0.45 & 0.31 & 0.02 \\
\hline 10 & BRRI dhan49 & 5.26 & 5.22 & 5.37 & 5.31 & 5.31 & 5.30 & -0.46 & $0.07^{*}$ & 0.00 \\
\hline 11 & BRRI dhan 11 & 4.23 & 4.22 & 4.22 & 4.17 & 4.20 & 4.21 & -1.55 & $0.03^{*}$ & 0.00 \\
\hline & Mean & 6.13 & 5.45 & 5.86 & 5.70 & 5.66 & 5.76 & & & \\
\hline & E index $(\mathrm{Ij})$ & 0.37 & -0.31 & 0.1 & -0.06 & -0.1 & & & & \\
\hline & $\mathrm{CV}(\%)$ & 3.81 & 5.76 & 12.74 & 8.35 & 4.45 & & & & \\
\hline & $\operatorname{LSD}(0.05)$ & 0.4 & 0.53 & 1.27 & 0.81 & 0.43 & & & & \\
\hline
\end{tabular}

* indicates slopes significantly different from the slope for the overall regression which is 1.00 .

E1= Gazipur, E2= Rangpur, E3= Faridpur, E4= Rajshahi and E5= Sonagazi.

The hybrid BRRI33A/BRRI26R, BRRI hybrid dhan4, SL-8H, BRRI7A/BRRI31R and IR79156A/BasmatiR showed positive and considerable phenotypic index $(\mathrm{Pi})$, insignificant regression coefficient (bi) and deviation from regression $\left(\mathrm{S}^{2} \mathrm{di}\right)$ which indicated that these hybrids were stable over all environments (Table 4). BRRI hybrid dhan3 showed positive phenotypic index (Pi), significant regression coefficient (bi) and insignificant deviation from regression $\left(S^{2}\right.$ di) which was stable in E1 and E3. Kulsum et al. (2013) observed that the promising hybrid II32A/BR12R was suitable for Gazipur location and another promising hybrid BR10A/BR13R was favorable for Comilla location. The grain yield was sensitive and highly influenced by environment resulting in 
higher $\mathrm{G} \times \mathrm{E}$ interaction under stress environments in rainfed ecosystem (Ouk et al., 2007).

Biplot analysis is possibly the most powerful interpretive tool for AMMI models. Biplots are graphs where aspects of both genotypes and environments are plotted on the same axes so that interrelationships can be visualized. There are two basic AMMI biplots, the AMMI 1 biplot where the main effects (genotype mean and environment mean) and IPCA1 scores for both genotypes and environments are plotted against each other and the AMMI 2 biplot where scores for IPCA1 and IPCA2 are plotted.

In AMMI 1 biplot, the usual interpretation of a biplot is that the displacements along the abscissa indicate differences in main (additive) effects, whereas displacements along the ordinate indicate differences in interaction effects. AMMI 2 biplot presents the spatial pattern of the first two PCA axes of the interaction effect corresponding to the genotypes and helps in visual interpretation of the GEI patterns and identify genotypes or locations that exhibit low, medium or high levels of interaction effects (Sharma et al. 1998). Points of either genotypes or environments which are near each other have similar interaction patterns while points distant from each other are different.

The AMMI 1 biplot gave a model fit $96.0 \%$. This result is agreed with the findings of Naveed et al., (2007); Gauch and Zobel (1996). Among the hybrids IR79156A/BRRI20R, BRRI hybrid dhan3, BRRI hybrid dhan4 and BRRI33A/BRRI26R exhibited high main effect with negative IPCA1 score (Fig. 1). Hence, they were identified as specifically adapted to favourable environments.

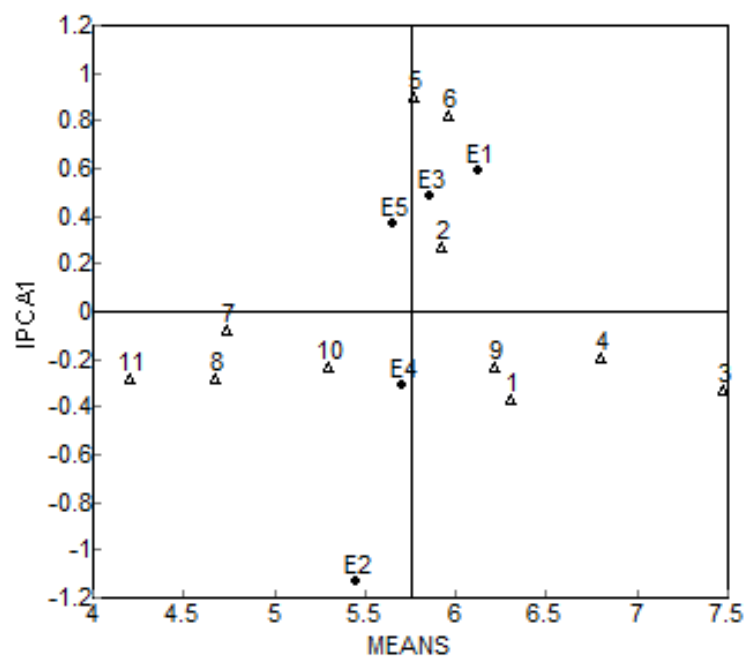

Fig. 1. Biplot of the first AMMI interaction (IPCA 1) score (Y-axis) plotted against mean yield (X-axis) for promising hybrid rice genotypes. 
The environments E4 had negative IPCA1 score and it is considered as favourable environment for these hybrids. On the other hand BRRI7A/BRRI31R, SL-8H and IR79156A/BasmatiR had positive IPCA score with high main effect. The environments E1 and E3 had positive IPCA1 score, it had positive interaction with these hybrids and these two were considered as the favorable environments for these hybrids. However, these hybrids had negative interaction with other environment (E4 and E2) as it possessed negative IPCA1 score. Genotypes near the origin are non sensitive to environmental interactive forces and those distant from the origins are sensitive and have large interaction (Muthuramu et al., 2011). Since IPCA2 scores also play a significant role in exploiting the GEI, the IPCA1 scores were plotted against the IPCA2 scores to further explore adaptation (Fig 2). According to figure 2 the hybrids BRRI33A/BRRI26R, IR79156A/BRRI20R, BRRI hybrid dhan3, BRRI hybrid dhan4, standard check variety BRRI dhan 49 and BR11 were close to the centre of the origin and showed to be more stable when plotting the IPCA1 and IPCA2 score.

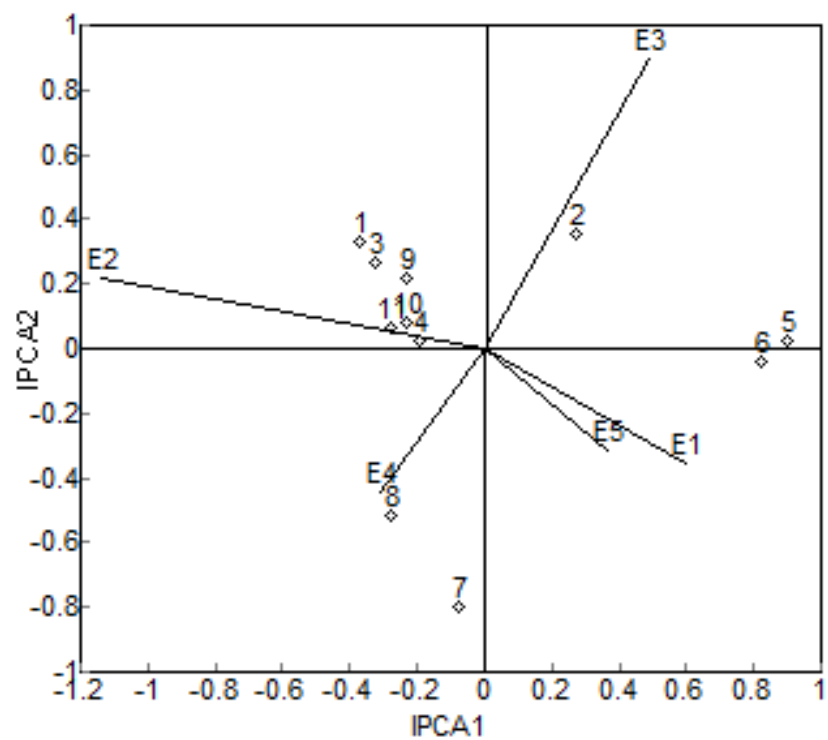

Fig. 2. Biplot of the first AMMI interaction (IPCA 2) score (Y-axis) plotted against AMMI interaction (IPCA 1) score (X-axis) for promising hybrid rice genotypes.

\section{Conclusion}

The hybrids BRRI7A/BRRI31R, IR79156A/BasmatiR, SL-8H, Heera and Teea were far from the centre of origin and showed instability due to their dispersed position. Environmental factors and genotype by environment interaction had the highest influence on the yield of those rice hybrids. The AMMI statistical model showed that the largest proportion of the total variation in grain yield was 
attributed to environments in this study. The hybrid BRRI33A/BRRI26R and IR79156A/BRRI20R had the highest yield and were hardly affected by the GEI effects as a result, they will perform well across a wide range of environments. The yield of BRRI7A/BRRI31R was also stable against environmental changes but its potential was lower than BRRI33A/BRRI26R and IR79156A/BRRI20R.

\section{References}

Aditya T.L., S. Ghosal, N. Sharma, M.R. Islam, R.R. Majumder, H. Khatun, R. Bhuiyan, F.M. Moinuddin, B. Karmakar and T.H. Ansari. 2010. General and specific adaptability through genotype-environment interactions of some somaclonal lines in rice. Bangladesh J. Progr. Sci. \& Technol. 8: 5-8.

Amirjani M.R. 2011. Effect of salinity stress on growth, sugar content, pigments and enzyme activity of rice. Int. J. Bot., 7: 73-81.

Anandan A., R. Eswaran, T. Sabesan and M. Prakash. 2009. Additive main effects and multiplications analysis of yield performances in rice genotypes under coastal saline environments. Adv. Biol. Res. 3: 43-47.

Bradu D. and K.R. Gabriel. 1978. The biplot as a diagnostic tool for models of two-way tables. Technometrics. 20: 47-68.

Gauch H.G. and R.W. Zobel. 1996. AMMI analysis of yield trials. In MS Kang and HG Gauch, (eds.). Genotype-by environment interaction. P. 85-122.

Gauch H.G. and R.W. Zobel. 1997. Identifying mega-environments and targeting genotypes. Crop Sci. 37: 311-326.

Gauch H.G. 1988. Model selection and validation for yield trials with interaction. Biometrics. 44: 705-705.

Honarnejad R., H. Dorosti, M.S. Mohammad Salehi and A. Tarang. 2000. Estimation of stability and adaptability of rice cultivars in different environmental conditions. Seed and Plant. 13: $32-43$

Kempton R.A. 1984. The use of biplots in interpreting variety by environment interactions. J. Agric. Sci. Camb. 103: 123-135.

Kulsum M.U., M.J. Hasan, A. Akter, H. Rahman and P.L. Biswas 2013. Genotypeenvironment interaction and stability analysis in hybrid rice: An application of additive main effects and multiplicative interaction. Bangladesh J. Bot. 42: 73-81.

Kulsum M.U., M.J. Hasan, M.N. Haque, M.S. Uddin and K.M. Iftekharuddaula 2015. Effect of genotype-environment interaction on grain yield of exotic rice (Oryza Sativa L.) hybrids. Bangladesh J. Bot. 44: 507-514.

Muthuramu S., S. Jebaraj and M. Gnanasekaran. 2011. AMMI biplot analysis for drought tolerance in rice (Oryza sativa L.). Res. J. Agric. Sci. 2: 98-100.

Naveed M. M. Nadeem and N. Islam. 2007. AMMI analysis of some upland cotton genotypes for yield stability in different milieus. World J. Agric. Sci. 3: 39-44.

Ouk M., J. Basnayake, M. Tsubo, S. Fukai, K.S. Fischer, S. Kang, S. Men, V. Thun and M. Cooper. 2007. Genotype-by-environment interactions for grain yield associated with water ability at flowering in rainfed low land rice. Field Crops Res. 101: 145154. 
Sharma P.K., P.K. Gupta and O.P. Govila. 1998. AMMI analysis of a pearl millet yield trial. Indian J. Genet. 58: 183-192.

Sheeba N.K., B.C. Viraktamath, S. Sivaramakrishnam, M.G. Gangashetti, P. Khera and R.M. Sundharam. 2009. Validation of molecular marker linked to fertility restorer gene(s) for WA-CMS lines of rice. Euphytica 167: 217-227.

Shrestha S.P., F. Asch, J. Dusserre, A. Ramanantsoanirine and H. Brueck. 2012. Climate effects on yield components as affected by genotypic responses to variable environmental conditions in upland rice systems at different altitudes. Field Crops Res. 134, 216-228.

Srividya A.L.R., A.S. Vemireddy, M. Hariprasad and Jayaprada S. Sridhar. 2010. Identification and mapping of landrace derived QTL associated with yield and its components in rice under different nitrogen levels and environments. Int. J. Plant Breed. Genet. 4: 210-227.

Vijayakumar C.H.M., M.I. Ahmed, B.C. Viraktamath, R. Balkrishnan and M.S. Ramesh. 2001. Genotypic x environment interaction effects on yields of rice hybrids in India. Indian J. Genetics. 61: 101-106.

Zobel R.W., M.J. Wright, H.G. Gauch. 1988. Statistical analysis of a yield trial. Agron. J. 80: $388-393$. 